\title{
Strategy Research on Computer Technology Applied in Economic Management of Enterprise
}

\author{
Jiaqi Liu \\ School of Economic and Management, Northwest University, Xi'an, China \\ Email: xaliujiaqi@yeah.net
}

Received 27 May 2015; accepted 15 June 2015; published 18 June 2015

Copyright (C) 2015 by author and Scientific Research Publishing Inc.

This work is licensed under the Creative Commons Attribution International License (CC BY).

http://creativecommons.org/licenses/by/4.0/

(c) () Open Access

\begin{abstract}
With continuous improvement of science and technology, computer technology has had an increasingly profound effect on economic management of enterprise, and it is increasingly important how to make the best of computer technology to improve the quality of economic management of enterprise. This paper briefly states the influence of computer technology on economic management of enterprise and application strategy of computer technology in economic management of enterprise.
\end{abstract}

Keywords

\section{Computer, Enterprise Economy, Economic Management, Strategy}

\section{Introduction}

Computer technology is the technical foundation of social progress and economic development. In the temporary society focusing on high-quality and high-efficiency, the most effective way for enterprises to keep up with the rapid path of economic development in the increasingly fierce market competition, is to change the traditional economic management mode of enterprise, reasonably introduce and use advanced computer management technology and formulate modern management mode conforming to the status of enterprises' development. Therefore, the existing problems of computer technology in economic management of enterprise are deeply explored and the effective strategies are analyzed to achieve the reasonable application of computer technology in economic management of enterprise with great practical significance in this paper. 


\section{The Role of Computer Technology in Economic Management of Enterprise}

Nowadays society is a modernized society stress on high quality and high efficiency, only by changing economic management mode of traditional enterprises, by reasonably introducing and applying advanced computer management technology, and by working out modernized management mode that conforming to the development state of enterprise itself, which is the most effective approach for enterprise to remain invincible in increasingly furious market competition.

\subsection{Influence Daily Office Work of Enterprise}

The most basic and most common work in daily business operation is file processing. File processing tends to featured with heavy workload and tedious work steps, and traditional way of manual handling not only be time-consuming and energy-consuming, but also easily induces human error during working process or neglects important issues, which can not ensure job content and work efficiency, even if the enterprise increase staff recruitment, it can not solve above mentioned issues basically. However, applying advanced computer technology can rescue employees from large amount of tedious and complex editing and sorting, which effectively relieve the condition of lacing of human resource for enterprise, and thus to greatly improve the overall work efficiency and quality in enterprise [1].

In addition, applying relevant computer software can help enterprise manager deal with daily management more effectively, which enable them to remote control the business management in mobile working, and solves the limitation problems of time and space to management [2]. Either manages or general staff in enterprise, they can deal with related issues happened in production and management in enterprise at anytime and anywhere

\subsection{Influence Financial Management of Enterprise}

Traditional enterprise operation and management mainly rely on financial staff's labor accounting to operate and process financial data, with the enlargement of enterprise scale, workload needed in finance is also gradually increasing, simple labor accounting and management mode causes the low work efficiency, and enterprise still need to consume large amount of human cost [3], but computer technology effectively solves this problem. The application of computer technology can help enterprise solve financial work more efficiently, for instance, during financial accounting, they can apply relevant computer software to inquire more conveniently and effectively, and they also can orderly store relevant fiscal information such as quarterly financial statement and quickly find information needed. At the same time, it also can avoid some human error, which improves the work efficiency and quality of financial work within enterprise [4].

\subsection{Influence the Future Development and Strategic Decision of Enterprise}

In terms of internal operation of enterprise, it lack of basic data information, production department, purchasing department, sales department or other related departments can not obtain relevant data for auditing in time, and financial information can not catch up with market changes, which will lead to that enterprise manager can not precisely make most suitable strategy decision in time, and it is not good for the long-term strategic development of enterprises.

Computer technology effectively helps enterprises realize timely update of data information, top management of enterprises can know all kinds of information related with enterprise overall operation more conveniently and precisely, and achieve real time monitoring, so as to make strategical decision for enterprise development in time based on market change [5], which is of great significance to the long-term development of enterprise in the whole market economy.

\subsection{Influence Cultural Construction of Enterprise}

With the emerging of instant messaging software like QQ and Wechat etc. and extensive application of various search engines, among staff of enterprise, among enterprises, and between enterprises and consumers, all of them can communicate more conveniently and quickly, which is good for enterprise to proceed cultural construction, brand establishment and log-term strategic development [6]. 


\section{Existing Problems of Computer Technology in Economic Management of Enterprise}

\subsection{The Polarization Phenomenon of Application of Computer Technology Is Very Serious}

Although enterprises in our country are paying more and more attention to computer technology, there is still obvious polarization phenomenon in the combination process of computer technology and economic management of enterprise. Comparing with large-scale enterprises, especially transnational joint venture enterprise, their basis of information construction is better, and their management mode is in line with international advanced mode, and they can quickly adapt to and promote the application of computer technology within the enterprise, and thus to really play the function of computer software and improve the work efficiency and job content of enterprise [7]; however, to most of small and medium-sized private enterprises, as their funding to computer technology is not enough and they can not well master the enterprise development of their own, so they always cannot go further because they encounter problems in the process of computer construction, and always give up halfway, or cause wasting of resource of computer technology, and they can not achieve promising results as expected.

\subsection{Staff's Cognition}

Most of enterprise managers and grass-roots staff have adapted to the traditional management mode and working mode of enterprise, especially enterprise managers, in their opinion, the change in economic management mode of enterprise will cause adverse impact on operation and development of enterprise, or they think that their enterprises can strive for survival in market competition, so they have a certain fluke mind and not willing to actively change. In addition, there are also some enterprise managers realize the importance of application of computer technology, but they do not well know about development orientation and demand of their own enterprises, which make them cannot correctly and effectively make use of existing computer technology, and cause wasting of resources [8]. As a result, abandoning traditional management mode and comprehensively correctly grasping the enterprise development strategy are of great significance in promoting computer technology in economic management of enterprise.

\section{Measure and Suggests to Enterprises When Proceed Economic Management by Applying Computer Technology}

\subsection{Know Their Own Demand}

If enterprises want to survive and be stable in furious market competition, they must follow the development mode that fit themselves and with their own features, avoid by all means to follow others blindly. Only by recognizing own development status and development orientation, really knowing own demand, and working out total planning based on practical situation, then enterprises can work out computer software that fitting own business procedures and business habits [9], which enable computer technology effectively used by enterprises.

\subsection{Reinforce Concept of All Aspects of Enterprise}

The most important element in enterprises is "person”. First of all, enterprise manager need to fully understand and pay enough attention to the necessity of application of computer technology. After enterprises introducing advanced computer technology, firstly grass-roots employees need to be trained for related knowledge, and improve their sense of identity for application of computer technology inwardly, let them know the convenience that computer technology brings in, and make both managers and employees can really realize the importance of computer technology in economic management of enterprise, only in this way that application of computer technology can be more effectively promoted, and avoid the situation of giving up halfway, and finally improve the overall work efficiency of enterprises and utilization of computer technology. Meanwhile, enterprises should also pay attention to reinforcing the protection of important data of enterprises, work out related confidentiality measures to prevent the disclosure of important documents.

\subsection{Reasonably Plan Business Capital}

In terms of structure of enterprises in our country now, most of them are small and medium-sized private enter- 
prises, and in these private enterprises, most decision makers' cognition on computer technology in economic management of enterprise is not perfect enough, usually enterprises will not put emphasis on construction of computer technology when funding, so how to effectively use related fund become especially important. As enterprises involve in extensive industries, and their state of operation and business process are not always changeless, so it is not necessary to blindly pursue most advanced science and technology when considering applying computer technology in economic management, instead should based on the own operation and necessary invested funds, to solve most urgent problems of enterprises and choose computer software fitting themselves scientifically and flexibly. After application of computer technology bringing in some economic benefits to enterprises, enterprises can properly increase the investment in funds and facilities to meets the needs of modern economic management.

\subsection{Cultivate Professional Technical Talents in Computer}

After enterprises working out rational computer software based on their own practical situation, professional talents are needed to operate and maintain them, in this way computer technology can be maximum used [10]. In the process of applying computer technology in economic management of enterprises, it is very necessary to reinforce training to enterprise employees in actual operation of computer program and software and technical training to professional talents.

\section{Conclusion}

With rapid development of modern market economy, competition among each enterprise gets increasingly furious, and multi-industry competition is also widely existing. Either leading enterprises in the industry or small and medium-sized private enterprises, if they want to improve their core market competitiveness, and remain invincible in furious market competition, both of them must change their economic management strategy continuously to better meet needs of economic development. As a result, scientifically and reasonably applying computer technology and improving its application efficiency in economic management of enterprises, are development trend of the era, as well as the need for enterprises to adapt to the scientific and technical revolution. Traditional economic management mode has already faced great challenge in complex and changeable market environment, and cannot realize need for strategic development of enterprise. Application of computer technology in economic management of enterprise can help enterprises make strategic adjustment quickly and effectively, and allocate and integrate various resources of good quality reasonably. However, various problems will inevitably occur during the combination process of computer technology and economic management of enterprises, which requires us to find and solve problems in the actual operation and make the computer technology serve enterprises better, and help enterprises realize rapid development.

\section{References}

[1] Su, W. (2014) Discussion on Application of Computer in Economic Management of Enterprise. Modern Economic Information, 109.

[2] Sun, T. (2014) Study on Application of Computer Technology in Management of Enterprise. Guide to Business, 64-65.

[3] Zeng, Q. and Huang, Q.H. (2014) The Empirical Study on Financing Governance of Computer Enterprise. Commercial Accounting, 105-106.

[4] Gu, J.Z. (2015) The Existing Problems and Strategies of Financing Governance of Computer Enterprise. Money China (Academic Edition), 102.

[5] Liu, J.J. (2013) Discussion on Application of Computer Technology in Modern Business Management. Private Science and Technology, 102

[6] Li, N. (2013) About Application of Computer Technology in Enterprises. Electronic Technology and Software Engineering, 102.

[7] Chen, C. (2014) Exploration of Network Construction in Large-Sized Computer Enterprise. Technological Development of Enterprise, 78-80.

[8] Chai, B.Q. and Wang, H.Y. (2014) Research on Computer Application in Economic Management of Enterprise. Market Modernization, 126

[9] Liu, H. (2013) About Application of Computer Technology in Enterprise’s Material Management. Modern Economic 
Information, 67.

[10] Du, Y.H. (2014) About Application of Computer Technology in Management of Enterprise. Digital Technology and Application, 216. 